\title{
A criança em Instituições de Acolhimento: $O$ que dizem as pesquisas científicas
}

Mariana Parro Lima. Universidade Federal de São Paulo.

\section{Resumo}

Este artigo é um estudo exploratório que tem como principal objetivo refletir sobre as pesquisas com crianças em Instituições de Acolhimento. Para isso, realizou-se um levantamento da produção científica brasileira sobre infância e instituições de abrigo cadastrada no banco de dados do Scielo, a partir dos descritores "infância", "criança", "instituição de acolhimento" e "abrigo", publicada no Brasil no período de 2010 a 2015. Com referência nos estudos da sociologia da infância, de autores como Corsaro, Qvortrup e Sarmento, buscou-se fazer uma análise crítica acerca de produções a respeito do tema instituição de acolhimento compreendendo a importância de uma discussão e reflexão acerca da institucionalização da criança.

Palavras-chaves: criança; infância; instituição de acolhimento; estatuto da criança e do adolescente.

\begin{abstract}
The child in Foster Institutions: What scientific research says. This article is an exploraty study that has as main objective to reflect about researches with children who live in institutional shelter. For such, a survey of Brazilian scientific production on childhood and foster institution was carried out in the Scielo database, using the descriptors "childhood", "child", "foster institution" and "shelter", published in Brazil in the period from 2010 to 2015. With reference in the studies of the sociology of childhood, authors such as Corsaro, Qvortrup and Sarmento, it was sought to make a critical analysis about productions on the topic of shelters, understanding the importance of a discussion and reflection about the practice of sheltering children.
\end{abstract} Keywords: child; childhood; foster institutions; children and adolescent code.

\section{Resumen}

El niño en instituciones de acogida: Lo que dicen las investigaciones científicas. Este artículo es un estudio exploratorio que tiene como principal objetivo reflexionar sobre las investigaciones con niños en Instituciones de Acogida. Para eso, se realizó un levantamiento de la producción científica brasileña sobre infancia e instituciones de abrigo registrada en el Banco de Datos del Scielo, a partir de los descriptores "infancia", "niño", "institución de acohida" y "abrigo", publicada en Brasil En el período de 2010 a 2015. Con referencia en los estudios de la sociología de la infancia, de autores como Corsaro, Qvortrup y Sarmento, se buscó hacer un análisis crítico acerca de producciones acerca del tema abrigos, comprendiendo la importancia de una discusión y reflexión acerca de la institucionalización del niño.

Palabras clave: niños; infancia; instituición de acogida; estatuto del niño y del adolescente. 
Nos últimos anos, a infância passou a ser investigada em sua pluralidade pelas mais diversas áreas científicas. Vem-se questionando a ideia da criança como potencialidade, promessa, um vir a ser, adulto futuro, já discutida por Rosemberg em 1976, ideia essa que deixa a criança em segundo plano, à espera de uma vida que virá. Esta mudança na compreensão da infância se dá quando, segundo Sarmento (2008), passamos a considerar que [...] as crianças integram uma categoria social, a infância, mas constroem processos de subjetivação no quadro da construção simbólica dos seus mundos de vida, estabelecendo com os adultos interações que as levam a reproduzir as culturas societais e a recriá-las nas interações de pares (p. 31).

Os estudos sociais da infância têm ocupado um espaço significativo no cenário internacional, por propor o importante desafio teórico-metodológico de considerar as crianças, atores sociais plenos (Corsaro, 2011; Prout, 2010; Qvortrup, 2010; Sarmento, 2003). Para Corsaro (2011), as crianças são responsáveis por suas infâncias e, logo, tem uma participação social bilateral: afetam e são afetadas pela sociedade. Com essa mesma convicção, Qvortrup (2010, p. 634) defende a infância enquanto estrutura social e fala sobre a demanda pela concessão de visibilidade à infância e de voz às crianças, ou seja, "lidar com a infância e as crianças por elas mesmas, sem ter de necessariamente fazer referência ao seu futuro".

A partir deste novo olhar, algumas mudanças foram necessárias em meio às práticas e políticas voltadas à criança, buscando assegurar sua proteção integral, o que pode ser observado com a criação de leis e normas que englobam várias áreas como saúde, educação, tutela, adoção, entre outros. O Estatuto da Criança e do Adolescente (ECA) de 1990 e a Lei Orgânica da Assistência Social (LOAS) de 1993 rompem com a figura do menor em situação irregular, e afirmam que crianças e adolescentes são universalmente sujeitos de direitos pela primeira vez na História (Marcílio, 2001). Inaugura-se um novo direcionamento para o cuidado e a educação de jovens e crianças, habilitando diferentes critérios para as instituições que os acolhem e afirmando o dever do Estado, da sociedade civil e das famílias em garantir e restaurar os direitos dos mesmos.

Assim sendo, é possível notar a multiplicação de estudos sobre a infância com foco na creche e na pré-escola, como crescente espaço para a reflexão sobre a construção social e cultural da mesma. Porém, alguns trabalhos desafiam olhar para outros cenários como a rua, os parques públicos, os assentamentos, as comunidades populares, hospitais e instituições de acolhimento $^{1}$ (Cohn, 2000; Feitosa, 2011; Fernandes, 1979; Gobbi \& Finco, 2011; Paula \& Silva Filho, 2012). Estes outros espaços também revelam a construção social e cultural da infância e, neste estudo, tornam-se palco para a discussão.

Quando feridas em alguns de seus direitos, crianças passam a ser responsabilidade do poder público, sendo levadas para instituições de acolhimento, que devem assegurar a proteção à integralidade das mesmas. O cuidado dessas crianças passa, então, a ser realizado por outras pessoas que não a família, o que acaba sendo, muitas vezes, um conflito para a criança. As condições que levaram esta criança ao afastamento de sua família também nos dão indícios de uma educação negligenciada, aumentando ainda mais as tensões vivenciadas por esses indivíduos.

Percebe-se que, mesmo com os esforços para preservar os vínculos familiares, muitas vezes a reintegração à família de origem deixa de ser possível e o acolhimento institucional acaba sendo a opção, ao menos provisoriamente, para preservar os direitos fundamentais a que uma criança faz jus.

Apesar de todas as garantias fornecidas por leis para a Educação Infantil (Ministério da Educação, 2009a, 2009b) e para a Proteção à Criança e ao Adolescente (CNAS/CONANDA, 2006; CNAS/CONANDA, 2009; ECA, 1990; Lei n. 12.010, 2009), ambos os contextos interacionais são, ainda hoje e com frequência, encarados como lugares sociais da criança "desamparada" e marcados por uma ideologia assistencialista ou filantrópica (Rossetti-Ferreira et al, 2012).

Em estudo que busca discutir as vulnerabilidades de crianças das periferias metropolitanas, Freitas e Mecena (2012) observam que são muitas as pesquisas que procuram avaliar crianças e adolescentes como sujeitos sociais, pois estes estão "entre os mais expostos a riscos iminentes, acumulados em decorrência de problemas ambientais, alimentares, de segurança e, principalmente, pela escassez de recursos somada à escassez de políticas públicas" (p. 196). Ainda assim, Qvortrup (2011) traz à tona o fato da infância ser ignorada nas análises econômicas e políticas mundiais ou nacionais, mesmo sabendo que todos os eventos, grandes ou pequenos, terão repercussões sobre as 
crianças, como parte da sociedade. Frente a isso, o autor aborda em suas pesquisas a questão de como se cuida da infância ou se presta atenção nela e qual sua posição na estrutura social da sociedade moderna.

Motivado por estes apontamentos, este estudo questiona quais caminhos estão sendo tomados para entender as crianças - aqui em questão, a criança em instituição de acolhimento. A partir de que compreensão de infância estão dialogando as pesquisas científicas atuais? Quais os métodos utilizados que possibilitam a expressão e escuta das crianças? Consideradas como sujeitos de direitos, as crianças passam a ser também consideradas como sujeitos de fala e, ao perceber que alguém fala por elas, faz-se imprescindível a elaboração de uma análise crítica. Desta forma, este estudo exploratório propõe observar estas questões a partir de um levantamento bibliográfico de pesquisas sobre crianças acolhidas, a fim de apontar os diferentes aspectos da institucionalização e refletir sobre as metodologias utilizadas para se falar sobre e com a criança nas pesquisas científicas.

\section{Infância e a pesquisa científica}

Visando maior aproximação com a problemática das pesquisas científicas sobre a criança em acolhimento institucional, foi realizado um estudo exploratório que teve como procedimento metodológico as técnicas de Análise de Conteúdo, que para Bardin (2002), refere-se a um método investigativo composto por um conjunto de técnicas de análise das comunicações que faz uso de procedimentos sistemáticos e objetivos de descrição do conteúdo das mensagens. A autora destaca a importância da organização para que esta análise seja realizada e aponta três polos norteadores: a pré-análise, a exploração do material e o tratamento dos resultados (inferência e a interpretação).

A pré-análise se deu com a busca de artigos científicos brasileiros cadastrados no Banco de Dados do Scielo ${ }^{2}$, em diferentes áreas do conhecimento. Utilizou-se como descritores de busca as palavras "infância", "criança", "instituição de acolhimento" e "abrigo" que, combinadas entre si, proporcionaram o recorte necessário para se chegar ao conjunto de textos que melhor representasse o escopo deste estudo. Esta coleta de dados teve como critérios artigos acadêmicos que tratassem do contexto da criança em acolhimento institucional, publicados entre os anos de 2010 e 2015, por revistas brasileiras que estão integralmente disponíveis na internet.

Durante a exploração do material, refletiu-se sobre as questões mais relevantes para a discussão aqui proposta. Analisando o que diziam os títulos e resumos dos textos encontrados no resultado da busca realizada, com o intuito de codificar os conteúdos abordados, foram, então, selecionados 16 artigos que constituíram o corpus definitivo desta pesquisa.

Para o tratamento dos resultados, última fase da Análise de Conteúdo, optou-se pela análise categorial da Análise de Conteúdo, definindo três categorias gerais, a partir da presença de um conjunto de características de conteúdos temáticos que aproximavam o diálogo entre as pesquisas escolhidas. Tais categorias são: "Pesquisas que tratam da Instituição de Acolhimento", "Pesquisas sobre as crianças em situação de Acolhimento Institucional" e "Pesquisas com Crianças em Instituições de Acolhimento", organizadas e apresentadas nas Tabelas 1, 2 e 3 respectivamente.

Com base nessa categorização dos artigos e para melhor exploração dos conteúdos, serão propostas a seguir, inferências e interpretações dos temas abordados, apontando algumas significações verificadas ao longo desta análise, seguindo como fio condutor os três tópicos referentes às categorias estipuladas.

\section{Pesquisas que Tratam da Instituição de Acolhimento}

Para abrir a reflexão sobre a infância em instituições de acolhimento, buscou-se os artigos que tratam deste espaço e de seus desdobramentos. Os artigos aqui escolhidos trazem um pouco do contexto institucional, da organização dos espaços, dos profissionais que estão envolvidos com o acolhimento das crianças e como estas relações se constroem dentro das instituições de acolhimento (Tabela 1).

Em seu artigo, Nascimento (2012) busca discutir o regulamento judicial que envolve o acolhimento de crianças, trazendo como ponto de partida a história brasileira sobre a proteção à infância. A autora destaca que, com o Estatuto da Criança e do Adolescente (ECA), não se pode mais abrigar por pobreza, indicando que "essa naturalização afirma que existiria uma verdade sobre como educar os filhos e que os colocar em estabelecimentos fechados seria um meio de inserção e de adaptação social" (p. 39). 
Tabela 1. Pesquisas que Falam sobre a Instituição de Acolhimento

\begin{tabular}{|c|c|c|c|}
\hline & Título & Autor & $\begin{array}{c}\text { Ano de } \\
\text { Publicação }\end{array}$ \\
\hline 1 & Contextos ecológicos em uma instituição de acolhimento para crianças. & $\begin{array}{l}\text { Rosa, E. M., Santos, A. P. dos, Melo, C. R. S., \& } \\
\text { Souza, M. R. }\end{array}$ & 2010 \\
\hline 2 & Abrigo, Pobreza e Negligência: percursos de judicialização. & Nascimento, M. L. & 2012 \\
\hline 3 & Perfil e trajetória de educadores em instituição de acolhimento infantil. & Cavalcante, L. I. C., \& Corrêa, L. S. & 2012 \\
\hline 4 & Perfil mediacional de mães sociais que atuam em instituições de acolhimento. & Tomás, D. N., \& Vectore, C. & 2012 \\
\hline 5 & Acolhimento institucional na assistência à infância: o cotidiano em questão. & Guedes, C. F., \& Scarcelli, I. R. & 2014 \\
\hline 6 & $\begin{array}{l}\text { Significados atribuídos por mães acerca do acolhimento institucional, } \\
\text { reintegração e rede de atendimento. }\end{array}$ & $\begin{array}{l}\text { Rocha, P. J., Arpini, D. M., \& Savegnago, S. } \\
\text { D. O. }\end{array}$ & 2015 \\
\hline
\end{tabular}

Porém, ao longo da leitura, fica explícito o quanto a situação de pobreza ainda está vinculada a história da institucionalização da criança, os chamados "filhos da pobreza". Um lugar no qual as crianças trazem marcas do abandono, de maus-tratos, do descaso, da privação; revelam, ainda, as marcas socialmente construídas, o estigma da criança pobre, o marginal. São estes os olhares que por muitos anos envolveram as práticas e políticas voltadas às instituições de acolhimento e, por isso, com as novas leis de cuidado e proteção à infância e à adolescência, faz-se necessária a ressignificação destas instituições.

Como nos aponta Sarmento (2011), "as mudanças na condição social da infância são desigualmente experimentadas pelas crianças e, elas próprias exprimem as transformações dos seus grupos sociais, étnicos e culturais de pertença" (p. 587).

Percebe-se, assim, a importância de observar o lugar por onde transitam as crianças, com o intuito de perceber como estão organizados os espaços e as rotinas nas instituições e quais as experiências possíveis quando essas crianças estão acolhidas. É este o fio condutor da pesquisa apresentada por Guedes e Scarcelli (2014). A partir da abordagem psicanalítica, as autoras se aproximam do objeto de pesquisa a fim de revelar o cotidiano dos serviços de acolhimento. Com um mosaico de cenas vão tecendo as relações vivenciadas no cotidiano institucional, revelando contradições, lacunas e excessos como parte da complexidade deste cotidiano. As autoras revelam que a escolha da metodologia "decorre da convicção sobre a importância de produções de conhecimento que tenham como origem os cotidianos institucionais e que retorne a eles, trazendo outros prismas de análise e contribuindo para a discussão das práticas realizadas" (p. 61).
A partir de uma abordagem macroestrutural, Qvortrup (2010) amplia a percepção da infância e de sua relação com a sociedade, investigando como as forças sociais atingem a vida das crianças pequenas. Segundo o autor, esta perspectiva é indispensável para se chegar a um consenso sobre a natureza desta relação. Norteada por parâmetros sociais, tais como parâmetros econômicos, políticos, culturais, discursivo, entre outros, cada estrutura geracional representa os entendimentos e ideologias sobre os indivíduos que dela fazem parte.

Apesar de estarem expostas aos mesmos parâmetros, cada uma das categorias geracionais sofre ou lida com estes impactos de maneira distinta, pois os meios, os recursos, a influência e o poder estão distribuídos diferentemente entre as categorias (Qvortrup, 2010). Da mesma maneira, devemos lembrar que, para além da categoria infância, as crianças vivenciam diferentes experiências de infância, dependendo da cultura na qual estão inseridas, da classe social a que pertencem, sua cor de pele, sua etnia, criando infâncias plurais.

A instituição de acolhimento, como espaço provisório, torna-se o novo cenário para as relações sociais destas crianças, no qual a educação e o cuidado são atravessados por múltiplos aspectos e exigem um movimento constante de reflexão sobre a prática exercida pelos diferentes profissionais envolvidos. Esta temática de interesse foi discutida pelos autores Cavalcante e Corrêa (2012) e Tomás e Vectore (2012). Utilizando como procedimento metodológico entrevistas e vídeos-gravações, ambos os artigos relacionados buscaram nos educadores e nas mães sociais o ponto de partida de reflexão sobre a formação daqueles que atuam diretamente com as crianças em situação de acolhimento. As pesquisas em questão mostram que 
ainda são incipientes os estudos que buscam ouvir os educadores sociais e as mães sociais, atores indispensáveis neste contexto de acolhimento. Evidencia-se a importância da capacitação contínua destes profissionais, a fim de repensar os modelos de práticas que constituem a assistência à infância.

Em meio aos diferentes sentimentos e sensações que desabrocham juntos às dificuldades de representar situações vivenciadas, as crianças se expressam pelas mais variadas linguagens e cabe àqueles que interagem mais de perto saber ler e compreender suas necessidades. Há uma preocupação com o desenvolvimento e crescimento bio/psico/social das crianças, que faz parte do cuidado e da proteção exigidos pela legislação que norteia as instituições direcionadas à criança.

Por isso, conhecer a trajetória dos profissionais responsáveis pelo cuidado diário das crianças acolhidas e o contexto da instituição podem auxiliar na busca por novas estratégias de mediação junto às crianças e, ainda, rever a forma de organização dos serviços de acolhimento institucional.

Com o intuito de trazer outra perspectiva sobre os serviços de acolhimento, Rocha, Arpini e Savegnago (2015) procuraram conhecer a experiência de mães de crianças e adolescentes reintegrados acerca do trabaIho realizado pela rede de atendimento. Os relatos das mães evidenciam a atuação integrada por parte da instituição de acolhimento. A preocupação também com a família e, não apenas, com as crianças acolhidas, e do "envolvimento de outros serviços da rede de atenção" (p. 119), podem revelar se a criação de leis que amparam e norteiam as instituições de acolhimento institucional estaria produzindo mudanças no cenário do acolhimento.

Observar, avaliar e compreender as instituições e seus agentes sociais é um dos caminhos necessários para assegurar o cuidado e a proteção das crianças e dos adolescentes em situação de vulnerabilidade social. As pesquisas que se comprometem com esta temática e procuram olhar mais de perto estes contextos e suas complexidades estão mostrando caminhos para elaboração de novas estratégias e modelos para a prática junto às crianças e aos adolescentes, a fim de legitimar a instituição de acolhimento como um lugar de proteção e cuidado à infância.

\section{Pesquisas sobre Crianças em Situação de Acolhimento Institucional}

Para além da percepção e compreensão do espaço, a discussão avança no intuito de salientar as possibilidades vivenciadas pelas crianças que se encontram afastadas de suas famílias por motivos distintos. Parece ser esta a grande preocupação que se faz presente nos artigos que compõem a segunda categoria de análise, apresentados na Tabela 2. Ao notar as particularidades do contexto institucional do acolhimento, alguns autores pretendem trazer à tona como o crescimento e desenvolvimento destas crianças é afetado por este cenário.

Tabela 2. Pesquisas sobre Crianças em Situação de Acolhimento Institucional
Título
Autor
Ano de Publicação

1 Vínculos entre crianças em situação de acolhimento institucional e visitantes da instituição.

2 O luto em instituições de abrigamento de crianças.

3 Um estudo sobre o acolhimento precoce inspirado no Método Bick.

4 Avaliação do crescimento e desenvolvimento de crianças institucionalizadas.

5 Estudo do "Age and Stages Questionnaires" com cuidadores de crianças institucionalizadas.

6 Linguagem receptiva e expressiva de crianças institucionalizadas.

7 Desempenho de vocabulário em crianças pré-escolares institucionalizadas.
Sousa, K. K., \& Paravidini, J. L. L.

2011

Tinoco, V., \& Franco, M. H. P.

2011

Golin, G., Benetti, S. P. da C., \& Donelli, T. M. S.

2011

Chaves, C. M. P., Lima, F. E. T., Mendonça, L. B.

A., Custódio, I. L., \& Matias, É. O.

2013

Cruz, E. J. S. da, Dias, G. B., \& Pedroso, J. S.

2014

Franco, E. C., Lopes, A. C., \& Lopes-Herrera, A. S.

2014

Misquiatti, A. R. N., Nakaguma, P. G., Brito, M.

C., \& Olivati, A.G.
2015 
A categorização dos artigos enquanto pesquisas sobre crianças se dá pela percepção da discussão que busca compreender estes atores sociais não enquanto sujeito da pesquisa, e sim, como objeto. São metodologias que avaliam, interpretam e configuram a criança exclusivamente pelo olhar do adulto. Pesquisas que utilizam a infância como "espaço" para se discutir algumas situações, ideias e pensamentos, que têm como foco as práticas e as intervenções realizadas pelos adultos para aquilo que se acredita ser o melhor para as crianças. Como argumentam Woodhead e Faulkner (2005), o Desenvolvimento da Criança é um corpo do conhecimento constituído por adultos para outros adultos, para ser usado no sentido de regular e promover a vida e a aprendizagem das crianças. Mais frequentemente, as ações e os pensamentos das crianças são interpretados de acordo com modelos de processos psicológicos, com estádios de relativa competência e/ou desvios da "normalidade" (p. 3).

Ao relacionar o desempenho entre crianças pré-escolares que se encontram em instituições de acolhimento e crianças que não foram separadas de suas famílias, autores verificam, com o auxílio de testes avaliativos e metodologias quantitativas, como e de que forma o ambiente de acolhimento e o afastamento familiar interferem nos padrões de "normalidade" do desenvolvimento infantil (Chaves et al, 2013; Franco, Lopes, \& Lopes-Herrera, 2014 e Misquiatti et al, 2015).

Os resultados destas pesquisas ilustram e reforçam, muitas vezes, a noção de que existe uma normalidade, um padrão de desenvolvimento e do crescimento. As crianças que já se encontram "marginalizadas", excluídas, são, também nas pesquisas, colocadas em oposição às crianças que vivem em ambientes considerados socialmente favoráveis, de normalidade familiar.

Sarmento (2015) faz uma crítica acerca da profunda invasão da indústria cultural na construção dos referencias que são utilizados no cotidiano de trabaIho e na relação com as crianças:

Quase sempre, esta contaminação discursiva dos mundos de vida das crianças confunde, perturba e desorienta mais do que esclarece. E, sobretudo, constitui um importante fator de colonização do pensamento por modelos estruturados e ideias fechadas, difusores da visão de uma "criança universal" inevitavelmente marcada pela matriz da classe e da cultura hegemônicas, raramente incentivando o pensamento crítico e disponibilizando apoios para uma ação socialmente contextualizada e eticamente comprometida com o bem-estar e os direitos da criança (p. 32).

Apesar da luta crescente pelo reconhecimento das crianças enquanto atores sociais, evidenciada nos estudos sociais da infância, algumas representações históricas foram cristalizadas e, ainda hoje, regem políticas e práticas voltadas às crianças.

Para Franco et al (2014), apesar das situações desfavoráveis que podem ser tomados como indicadores de risco ao desenvolvimento infantil, não houve uma diferença significativa entre os dois grupos analisados quanto ao desempenho de linguagem, demostrando a relevância das relações estabelecidas entre crianças em acolhimento institucional e os educadores sociais. Já os autores Chaves et al (2013) e Misquiatti et al (2015) notaram a diferença entre os grupos, acentuando a importância de um acompanhamento periódico das crianças para que os profissionais possam realizar estratégias que favoreçam o desenvolvimento integral das mesmas.

Tinoco e Franco (2011), por sua vez, priorizaram um estudo qualitativo para conhecer e refletir sobre o luto em instituições de acolhimento de crianças. Buscou-se trazer para a experiência da institucionalização das crianças acolhidas a importância de lidar com a formação e rompimento de vínculos a partir da Teoria do Apego. É destacado, aqui, o olhar do adulto. Para a análise foram utilizados recortes de supervisões de cinco cuidadoras (assistente social, pedagoga e psicopedagoga) que trabalhavam em instituições de acolhimento e participavam de um grupo de supervisão em psicologia coordenado por uma das autoras do artigo em questão.

Esta situação de evidenciar a perspectiva do adulto também é percebida na pesquisa de Sousa e Paravidini (2011), que discute a forma vincular do apadrinhamento afetivo ${ }^{3}$ - processo vigente em muitas instituições de acolhimento - a partir da análise de entrevistas abertas realizadas com madrinhas que se dispuseram a falar sobre a relação com as crianças acolhidas. Fica a impressão de que falta o outro lado da história, também importante para compreensão tanto do luto quanto do vínculo afetivo. Ouvir também aqueles que estão passando pelo luto da perda e do rompimento com os familiares. Dar espaço para que as crianças abrigadas e que foram apadrinhadas possam falar sobre sua experiência com as madrinhas que as escolheram. 
Não se trata, aqui, de menosprezar os métodos quantitativos ou de desvalorizar as pesquisas que falam sobre as crianças, mas de compreender a importância, em igual escala, de pesquisas que tragam as crianças como sujeitos da pesquisa, que abram espaços para as falas das crianças junto às pesquisas científicas, àquelas que se debruçam sobre as questões da infância partindo do pressuposto de que a criança é um ator social, protagonista em suas próprias experiências (Corsaro, 2011; Sarmento, 2003; 2015).

\section{Pesquisas com Crianças em Acolhimento Institucional}

Apesar do número crescente de pesquisas sobre a infância, a criança e suas relações sociais, um número pequeno destas, ainda hoje, pretende revelar o olhar da criança em si. Este tópico ilustra essa situação ao apresentar para a reflexão apenas três dos 16 artigos selecionados para análise neste trabalho.

Feitosa (2011) fala sobre este desafio em relação aos estudos que buscam a perspectiva das crianças - suas vozes -, acentuando ainda mais esta análise quando a voz a ser ouvida vem de crianças que vivem em situação de vulnerabilidade social. Perspectivas que provocam, incomodam, desafiam.

A partir dos artigos escolhidos, como evidenciado na Tabela 3, é possível perceber que existem autores interessados neste desafio.

Tabela 3. Pesquisas com Crianças em Acolhimento Institucional.

\begin{tabular}{|c|c|c|c|}
\hline & Título & Autor & Ano de Publicação \\
\hline 1 & $\begin{array}{l}\text { Fatores relacionados à institucionalização: perspectivas de crianças vítimas de } \\
\text { violência intrafamiliar. }\end{array}$ & $\begin{array}{l}\text { Gabatz, R. I. B., Padoin, S. M. M., } \\
\text { Neves, E. T., \& Terra, M. G. }\end{array}$ & 2010 \\
\hline 2 & $\begin{array}{l}\text { Do faz de conta à realidade: compreendendo o brincar de crianças } \\
\text { institucionalizadas vítimas de violência por meio do brinquedo terapêutico. }\end{array}$ & Giacomello, K. J., \& Melo, L. L. & 2011 \\
\hline 3 & Escuta afetiva: possibilidades de uso em contextos de acolhimento infantil. & $\begin{array}{l}\text { Trivellato, A. J., Carvalho, C., \& } \\
\text { Vectore, C. }\end{array}$ & 2013 \\
\hline
\end{tabular}

Em discussão sobre as questões teóricas e epistemológicas de pesquisa com crianças, Ferreira (2010) demonstra que "se admite que as próprias experiências das crianças do que é ser criança e do que é a sua relação com os adultos são contributos inestimáveis para entender a infância" (p. 155). Por isso, é pertinente refletir sobre como se lida, então, com a criança nos ambientes institucionalizados, trazendo o olhar e a experiência da própria criança.

Entra em cena a criança como sujeito na pesquisa, participando e sendo envolvida no processo de pesquisa ativamente. Isso não quer dizer que seja a criança a protagonista na pesquisa, mas considera-la já é um grande passo na história da infância. Esta mudança de perspectiva traz em si o desafio de pensar métodos de pesquisa ou maneiras outras que deem conta de revelar o que pensam, sentem e dizem as crianças pequenas acerca do contexto em que estão inseridas.

Corsaro (2009), em suas pesquisas com crianças, apresenta o conceito de reprodução interpretativa e neste compreende a ideia da contribuição ativa da criança para a preservação e mudança social. Explica o autor que o termo interpretativa captura os aspectos inovadores da participação das crianças na sociedade, indicando o fato de que as crianças criam e participam de suas culturas de pares singulares por meio da apropriação de informações do mundo adulto de forma a atender aos seus interesses próprios enquanto crianças. O termo reprodução significa que as crianças não apenas internalizam a cultura, mas contribuem ativamente para a produção e a mudança social (p. 31).

Portanto, o autor salienta a importância de se conhecer as crianças e suas infâncias para entender a sociedade e suas complexidades. Prado, Vicentin e Rosemberg (2017) apontam, a partir de uma revisão da literatura brasileira que aborda reflexões sobre a ética em pesquisa com crianças, que "as recomendações sobre privilegiar metodologias participativas por permitirem relações mais horizontais entre os atores e 
maior riqueza nas informações foram recorrentes nos textos analisado" (p. 22).

Atualmente observa-se que o cenário vem se modificando nos últimos anos com os estudos que assumem as referências da sociologia da infância, reservando às crianças um lugar ativo na sociedade. A partir da década de 90 , rompem-se os tradicionais limites da investigação reservada aos campos médicos, da psicologia do desenvolvimento, para, então, considerar o fenômeno social da infância, concebida como categoria social autônoma, podendo assim ser analisada nas suas relações com a ação e estrutura social (Sarmento \& Pinto, 1997).

Assim sendo, encaramos que a criança modifica o espaço social em que vive, trazendo outras intepretações e reinventando o mundo dos adultos. Segundo Corsaro (2011) as crianças vão além da cultura dos adultos, construindo uma cultura exclusivamente delas, em pares, contribuindo de maneira ativa para a produção e mudanças culturais. É o que o autor denominou de cultura de pares, sendo esta um "conjunto estável de atividades ou rotinas, artefatos, valores e preocupações que as crianças produzem e compartilham em interação com as demais" (Corsaro, 2011, p. 128).

Giacomello e Melo (2011) buscam na fenomenologia o referencial para esta aproximação da criança na pesquisa, pois apontam que esta "não considera diante de si o ser humano como seu objeto de pesquisa, mas um sujeito que tem um mundo a ser desvelado" (p. 1573). Nas sessões de brinquedo terapêutico, os pesquisadores observam o faz de conta e apreendem as questões sobre a instituição de acolhimento trazidas pelas crianças.

Trivellato, Carvalho e Vectore (2013), por sua vez, adotaram o que chamaram de escuta afetiva como metodologia para conhecer o processo de acolhimento vivenciado pelas crianças. Para isso, valeu-se de diferentes instrumentos como entrevistas semiestruturadas, atividades lúdicas, construção de álbum como registro da história das crianças, observação da rotina institucional e contos de fadas. Dois pontos levantados pelos autores merecem destaque nesta reflexão: a indisponibilidade ou inexistência de registros contendo informações familiares, implicando na construção da identidade pessoal dessas crianças, e a necessidade de políticas públicas que possam efetivamente contribuir para a formação e reconhecimento de educadoras e mães sociais.

Com o intuito de compreender os fatores relacionados à institucionalização de crianças vítimas de violência intrafamiliar, Gabatz et al (2010) investigaram duas instituições de abrigo localizadas em município do interior do sul do Brasil. Nesta categoria de pesquisas com a participação das crianças, utilizaram como metodologia as Dinâmicas de Criatividade e Sensibilidade (DCS), pautadas em encontros grupais, selecionando as dinâmicas "Brincar em cena" e "Corpo Saber". Estas dinâmicas são fundamentadas no Método Criativo e Sensível, subsidiado pela pedagogia crítico-reflexiva de Paulo Freire, e propõem um espaço de discussão coletiva, na qual a experiência vivenciada é trabaIhada a partir de produções artísticas. Ouvir as crianças, para as autoras, "possibilita conhecer seus sentimentos e perspectivas e assim aproximar-se de suas necessidades, possibilitando uma assistência específica e integral, a fim de auxiliá-las a minimizar as implicações da institucionalização" (p. 672).

Compreende-se que as informações oriundas das próprias crianças são de suma importância para que, em nível mais macro, se possa ter uma melhor adequação das políticas de proteção e atendimento à infância a cada realidade contextual.

Nas palavras de Alderson (2005) "reconhecer as crianças como sujeitos em vez de objetos de pesquisa acarreta aceitar que elas podem "falar" em seu próprio direito e relatar visões e experiências válidas" (p. 423). O caminho adotado pelos pesquisadores desta última categoria de artigos foi a utilização do Termo de Assentimento voltado para a própria criança, deixando claro o objetivo da pesquisa e a liberdade de participar (ou não) da pesquisa.

\section{Considerações finais}

Quando, enquanto pesquisador, coloca-se o desafio de estudar a infância e a criança em instituições de acolhimento, torna-se imprescindível levar em consideração a vivência trazida pelas crianças, saber o que elas trazem abrigado consigo, qual história é contada através de seus gestos, das palavras, dos desenhos, dos movimentos e das múltiplas linguagens presentes no mundo das crianças. Se a intenção dos estudos aqui relacionados é a de compreender, questionar e refletir sobre a infância e as crianças em situação de vulnerabilidade social, como não fazê-lo também com o olhar daquelas que são as maiores interessadas?

Alguns pesquisadores ainda utilizam a expressão "dar voz às crianças" ao ressaltar a importância da participação das crianças nas pesquisas. Talvez o

Estudos de Psicologia, 23(3), julho a setembro de 2018, 271-281 
mais apropriado fosse dar ouvido e espaço para que as crianças possam falar, ou seja, fazer uso da voz que é inerente a estas. Como defende Lee (2010), as crianças têm voz em abundância, a questão é que lugar das práticas de voz ocupam as falas das crianças, indicando a ausência destas nas tomadas de decisão dentro das instituições formais.

A ausência das crianças também pôde ser percebida nesta análise, que apresentou apenas três artigos na última tabela, realçando a necessidade de mais pesquisas com crianças em acolhimento institucional, atentando-se, ainda, para a importância do debate sobre esta temática nos assuntos das políticas públicas.

Se, como nos aponta Qvortrup (2011), todos os eventos, grandes ou pequenos, terão repercussão sobre as crianças, como parte da sociedade, essas também terão reivindicações a serem consideradas. Quando o debate gira em torno de crianças que se encontram em instituições de acolhimento, é de seus direitos que se está tratando e, por isso, ouvi-las pode contribuir substancialmente para o adequado atendimento de suas necessidades pelo adulto e para a tomada de decisão sobre suas vidas.

Os artigos apresentados na categoria Pesquisas com Crianças em Acolhimento Institucional nos mostram alguns caminhos possíveis da pesquisa com crianças: através da observação e/ou interação em suas brincadeiras e jogos, registrando suas falas e gestos; registros escritos, desenhos, vídeos, diversos instrumentos que, quando utilizados junto às crianças, acabam por revelar suas próprias concepções sobre o contexto social em que estão inseridas.

Como destaca Sarmento (2003), ao tratar das crianças, não é apenas sobre elas que nos referimos: "este esforço, que é simultaneamente, analítico e crítico, na interpretação dos mundos sociais e culturais da infância, e político e pedagógico, na concepção da mudança das instituições para as crianças, [...] permitir-nos-á rever o nosso próprio mundo" (p. 15).

Trabalhar com a proposta de escutar, conversar e respeitar a criança pode proporcionar a ela o direito de participar das decisões relacionadas ao seu processo de crescimento e desenvolvimento. Pode, ainda, revelar dados importantes para repensar as condutas e práticas exercidas pelos profissionais envolvidos com as instituições de acolhimento, colaborando com a melhoria destes espaços e garantindo o cuidado e a proteção adequados para a criança.
Reconhece-se, ainda, a importância de trabalhos como este, de sistematização das pesquisas que tratam do acolhimento institucional, para os pesquisadores da área, no intuito de reconhecer e sintetizar as evidências científicas acerca da situação da institucionalização de crianças em vulnerabilidade social, para fundamentar as propostas de políticas de proteção e atendimento à infância.

\section{Referências}

Alderson, P. (2005). As crianças como pesquisadores: os efeitos dos direitos de participação sobre a metodologia de pesquisa. Educação e Sociedade'26(91), 419-442. doi: 10.1590/S0101-73302005000200007

Bardin, L. (2002). Análise de conteúdo. Lisboa: Edições 70.

Brasil. (2009a). CNE/MEC n5, de 17 de dezembro de 2009. Estabelece Diretrizes Curriculares para a Educação Infantil. Diário Oficial da União, Brasília, 17 dez. Seção 1, p. 18.

Brasil. (2009b). Indicadores da Qualidade na Educação Infantil. Ministério da Educação. Brasília, DF.

Cavalcante, L. I. C., \& Corrêa, L. S. (2012). Perfil e trajetória de educadores em instituição de acolhimento infantil. Caderno de Pesquisa, 42(146), 494-517. doi: 10.1590/S0100-15742012000200010

Chaves, C. M. P., Lima, F. E. T., Mendonça, L. B. A., Custódio, I. L., \& Matias, É. O. (2013). Avaliação do crescimento e desenvolvimento de crianças institucionalizadas. Revista Brasileira de Enfermagem, 66(5), 668-674. doi: 10.1590/S0034-71672013000500005

CNAS/CONANDA (2006). PNCFC - Plano Nacional de Promoção, Defesa e Garantia do Direito de Crianças e Adolescentes à Convivência Familiar e Comunitária (2 $2^{\underline{a}}$ edição). Aprovado pela Resolução Conjunta CNAS/CONANDA oㅜ1/2006, de 13 de dezembro de 2006. Brasília, DF.

CNAS/CONANDA (2006). Orientações Técnicas: Serviços de Acolhimento para Crianças e Adolescentes. Aprovado pela Resolução Conjunta CNAS/CONANDA no 1/2009, de 18 de junho de 2009. Brasília, DF.

Cohn, C. (2000). A criança indígena: a concepção Xikrin de infância e aprendizado (Dissertação de Mestrado). Recuperado de http:// dedalus.usp.br/F/XEPXBQU796JXVVIRGSK67KTI3DIX1TFQ2I727A V936L9SCM3J2-11297?func=direct\&doc_number $=001074056 \&$ pds handle=GUEST

Corsaro, W. A. (2009). Reprodução interpretativa e cultura de pares. In F. Müller \& A. M. A. Carvalho (Orgs.), Teoria e prática na pesquisa com crianças: diálogos com Willian Corsaro. (pp.31-50). São Paulo: Cortez.

Corsaro, W. A. (2011). Sociologia da infância (2 $2^{\mathrm{a}}$ ed.). Porto Alegre: Artmed.

Feitosa, A. G. S. (2011). A infância abrigada: impressões das crianças na Casa Abrigo (Dissertação de Mestrado). Recuperado de https:// www.lume.ufrgs.br/handle/10183/35148

Fernandes, F. (1979). As Trocinhas do Bom Retiro: contribuição ao estudo folclórico e sociológico dos grupos infantis. In F. Fernandes (Org.), Folclore e mudança social na cidade de São Paulo. (2 $2^{\underline{a}}$ ed., pp. 153-258). Petrópolis: Vozes.

Ferreira, M. (2010). “- Ela é nossa prisioneira!” Questões teóricas, epistemológicas e ético-metodológicas a propósito dos processos de obtenção da permissão das crianças pequenas numa pesquisa etnográfica. Reflexão e Ação 18(1), 151-182. doi: 10.17058/rea. v18i2.1524 
Franco, E. C., Lopes, A. C., \& Lopes-Herrera, S. A. (2014). Linguagem receptiva e expressiva de crianças institucionalizadas. Revista CEFAC, 16(6), 1837-1841. doi: 10.1590/1982-021620149713

Freitas, M. C., \& Mecena, E. H. (2012). Vulnerabilidades de crianças que nascem e crescem em periferias metropolitanas: notícias do Brasil. Revista Latinoamericana de Ciencias Sociales, Niñez y Juventud, 10(1), 195-203. Recuperado de http://www.redalyc.org/articulo. oa? $\mathrm{id}=77323982011$

Gabatz, R. I. B., Padoin, S. M. M., Neves, E. T., \& Terra, M. G. (2010). Fatores relacionados à institucionalização: perspectivas de crianças vítimas de violência intrafamiliar. Revista Gaúcha de Enfermagem, 31(4), 670-677. doi: 10.1590/S1983-14472010000400009

Giacomello, K. J., \& Melo, L. L. (2011). Do faz de conta à realidade: compreendendo o brincar de crianças institucionalizadas vítimas de violência por meio do brinquedo terapêutico. Ciência \& Sociedade Coletiva 16(supl. 1), 1571-1580. doi: 10.1590/ S1413-81232011000700093

Gobbi, M., \& Finco, D. (2011). Tod@s na foto: meninos e meninas fotografam o cotidiano no assentamento Dom Tomás Balduíno. Revista Trama Interdisciplinar. 2(2), 44-57. Recuperado de http:// editorarevistas.mackenzie.br/index.php/tint/article/view/4418

Guedes, C. F., \& Scarcelli, I. R. (2014). Acolhimento institucional na assistência à infância: o cotidiano em questão. Psicologia \& Sociedade, 26(n. spe.), 58-67. doi: 10.1590/S0102-71822014000500007

Lee, N. (2010). Vozes das crianças, tomada de decisão e mudança. In F. Müller (Org.), Infância em perspectiva: políticas, pesquisas e instituições (pp. 42-64). São Paulo: Cortez.

Lei n. 8069, de 13 de julho de 1990. (1990, 13 de julho). Estatuto da criança e do adolescente (ECA). Dispõe sobre a proteção integral à criança e ao adolescente. Diário Oficial da União, Seção 1.

Lei n. 8.742, de 7 de dezembro de 1993. (1993, 7 de dezembro). Lei Orgânica da Assistência Social (LOAS). Dispõe sobre a organização da assistência social e dá outras providências. Diário Oficial da União, Seção 1 .

Lei n. 12.010, 2009, de 3 de agosto de 2009. (2009, 3 de agosto). Dispõe sobre adoção; altera as Leis nos 8.069, de 13 de julho de 1990 Estatuto da Criança e do Adolescente, 8.560, de 29 de dezembro de 1992; revoga dispositivos da Lei $n^{\circ} 10.406$, de 10 de janeiro de 2002 - Código Civil, e da Consolidação das Leis do Trabalho - CLT, aprovada pelo Decreto-Lei $n^{\circ} 5.452$, de 10 de maio de 1943; e dá outras providências. Diário Oficial da União, Seção 1.

Marcilio, M. L. (2001). A roda dos expostos e a criança abandonada na história do Brasil. In M. C. Freitas (Org.), História social da infância no Brasil (pp. 53-79). São Paulo: Cortez.

Misquiatti, A. R. N., Nakaguma, P. G., Brito, M. C., \& Olivati, A. G. (2015). Desempenho de vocabulário em crianças pré-escolares institucionalizadas. Revista CEFAC, 17(3), 783-791. doi: 10.1590/1982-0216201513814

Nascimento, M. L. (2012). Abrigo, pobreza e negligência: percursos de judicialização. Psicologia \& Sociedade, 24(n. spe), 39-44. doi: 10.1590/S0102-71822012000400007

Paula, E., \& Silva Filho, J. J. (2012). As brincadeiras das crianças de um quilombo catarinense: imaginação, criatividade e corporalidade. In M. G. Arroyo \& M. R. Silva (Orgs.), Corpo infância: exercícios tensos de ser criança - por outras pedagogias dos corpos (pp. 184-211). Petrópolis: Vozes.
Prado, R. L.C., Vicentin, M. C., \& Rosemberg, F. (2017). Ética na pesquisa com crianças: uma revisão da literatura brasileira das ciências humanas e sociais. Childhood \& Philosophy, 14(29), 43-70. doi: 10.12957/childphilo.2018.30542

Prout, A. (2010). Reconsiderando a nova sociologia da infância. Cadernos de Pesquisa, 40(141), 729-750. doi: 10.1590/ S0100-15742010000300004

Qvortrup, J. (2010). A infância enquanto categoria social. Educação e Pesquisa'36(2), 631-643. doi: 10.1590/S1517-97022010000200014

Qvortrup, J. (2011). Nove teses sobre a "infância como um fenômeno social”. Pro-Posições. 22(1), 199-211. doi: 10.1590/ S0103-73072011000100015

Rocha, P. J., Arpini, D. M., \& Savegnago, D. O. (2015). Significados atribuídos por mães acerca do acolhimento institucional, reintegração e rede de atendimento. Psicologia: Ciência e Profissão, 35(1), 111-124. doi: 10.1590/1982-3703002312013

Rosemberg, F. (1976). Educação para quem? Ciência e Cultura'28(12), 1466-1471

Rossetti-Ferreira, M. C., Almeida, I. G., Costa, N. R. A., Guimarâes, L. A., Mariano, F. N., Texeira, S. C. P., \& Serrano, S. A. (2012). Acolhimento de crianças e adolescentes em situações de abandono, violência e rupturas. Psicologia: Reflexões e Crítica'25(2), 390-399. doi: 10.1590/ S0102-79722012000200021

Sarmento, M. J. (2003). Imaginário e culturas infantis. Cadernos de Educação, (21), 51-59. doi: 10.15210/CADUC.V0I21

Sarmento, M. J. (2008). Sociologia da Infância: correntes e confluências. In M. J. Sarmento \& M. C. S. Gouvea (Orgs.), Estudos da infância: educação e práticas sociais (pp. 17-39). Petrópolis: Vozes.

Sarmento, M. J. (2011). A Reinvenção do ofício de criança e de aluno. Atos de Pesquisa em Educação 6(3), 581-602. doi: 10.7867/1809-0354.2011v6n3p581-602

Sarmento, M. J. (2015). Uma agenda crítica para os estudos da criança Currículo sem Fronteiras 15(1), 31-49. Recuperado de http://www. curriculosemfronteiras.org/vol15iss1articles/sarmento.pdf

Sarmento, M. J., \& Pinto, M. (1997). As crianças e a infância: definindo conceitos, delimitando o campo. In M. J. Sarmento (Org.), As crianças: contextos e identidades. (pp. 7-30). Braga: Centro de Estudos da Criança/Universidade do Minho.

Sousa, K. K., \& Paravidini, J. L. L. (2011). Vínculo entre crianças em situação de acolhimento institucional e visitantes da instituição. Psicologia: Ciência e Profissão 31(3), 536-553. doi: 10.1590/ S1414-98932011000300008

Tinoco, V., \& Franco, M.H. P. (2011). O luto em instituições de abrigamento de crianças. Estudos de Psicologia' 28(4), 427-434. doi: 10.1590/ S0103-166X2011000400003

Tomás, D. N., \& Vectore, C. (2012). Perfil mediacional de mães sociais que atuam em instituições de acolhimento. Psicologia: Ciência e Profissão, 32(3), 576-587. doi: 10.1590/S1414-98932012000300005

Trivellato, A. J., Carvalho, C., \& Vectore, C. (2013). Escuta afetiva: possibilidades de uso em contextos de acolhimento infantil. Psicologia Escolar e Educacional, 17(2), 299-307. doi: 10.1590/ S1413-85572013000200012

Woodhead, M., \& Faulkner, D. (2005). Sujeitos, objectos ou participantes? Dilemas da investigação psicológica com crianças. In P. Christensen \& A. James (Orgs.), Investigação com crianças: perspectivas e práticas (pp. 1-28). Porto: Escola Superior de Educação de Paula Frassinetti. 
1. Esta terminologia substituiu a de abrigo e abrigamento após a nova lei de adoção Lei Federal no. 12010/2009 e neste texto é utilizada como contribuição da legitimação desta instituição tão fortemente marcada por preconceitos ao longo de sua história.

2. O Scientific Eletronic Library Online (Scielo) é uma biblioteca eletrônica que abrange uma coleção selecionada de revistas científicas brasileiras, que pode ser acessada pelo link http://www.scielo.br/.

3. O apadrinhamento afetivo é um programa que permite aos acolhidos a oportunidade de construção de laços afetivos para além daqueles vivenciados dentro da instituição de acolhimento, fortalecendo a convivência familiar e comunitária.

Mariana Parro Lima, Mestrado em Educação pela Universidade Estadual de Campinas (UNICAMP), é Doutoranda em Educação e Saúde na Infância e na Adolescência pela Universidade Federal de São Paulo (UNIFESP), Bolsista CAPES.

Endereço para correspondência: Rua Antonio Dair Augusti, 100,

Terras de Piracicaba 3, Piracicaba/SP. CEP: 13.403-857.

Telefone: (11) 99848-9555. E-mail: mariparro@hotmail.com

Recebido em 03.Mai.18

Revisado em 26.Jun.18

Aceito em 31.Jan.19 